\title{
STREET CHILDREN IN INDIA: A STUDY ON THEIR ACCESS TO HEALTH AND EDUCATION
}

\begin{abstract}
Nilika Dutta
Abstract: Street life is a challenge for survival, even for adults, and is yet more difficult for children. They live within the city but are unable to take advantage of the comforts of urban life. This study focused primarily on access to health and education in street children from 6 to 18 years old in the Indian metropolises of Mumbai and Kolkata. The study also aimed to assess the role of social work interventions in ensuring the rights of street children. A combination of quantitative and qualitative research methodologies was used. Convenience sampling was used to recruit 100 children. Data were collected on a one-to-one basis through semi-structured interview schedules and by non-participant observation. Findings revealed that extreme poverty was the primary cause for the increasing numbers of street children. Lack of awareness among illiterate parents regarding educational opportunities kept most children away from school attendance. Factors such as lack of an educational ambience at home made it difficult for the children to work on their lessons outside the premises of the institution. It was evident that those living with their parents had better access to health care facilities than did those living on their own; however, nongovernmental organizations made significant efforts to redress this imbalance, setting up health check-up camps at regular intervals. Although exposure to harsh reality at an early age had resulted in a premature loss of innocence in most, making them sometimes difficult to work with, the nongovernmental organizations were striving to ensure child participation and the growth of individual identity. The interventionists therefore focused on developing a rightsbased approach, rather than a charitable one.
\end{abstract}

Keywords: street children, rights, social intervention, health, education, India

Nilika Dutta is a research scholar at the Centre for Human Rights, School of Social Sciences, University Of Hyderabad 500 046, Telengana, India. Email: nilikadutta@gmail.com 
International Journal of Child, Youth and Family Studies (2018) 9(1): 69-82

The Juvenile Justice (Care and Protection of Children) Act of 2015 is concerned with children in two broad categories: those in need of care and protection, and those in conflict with the law. Street children may fall within both categories simultaneously, as children who are not provided with care and protection may end up in conflict with the legal system.

Over the years, various researchers and organizations have attempted to provide concise definitions of the term "street children". de Moura (2002) analysed the media and literature on these children and found that the use of the term "street children" is predominant in Latin America, Asia, Africa, and Eastern Europe, while the term "homeless children" is used in North America and Western Europe. Dabir and Athale (2011) mentioned that the United Nations has provided a broad definition: "those for whom the street (in the widest sense of the word, i.e. unoccupied dwellings, wasteland, etc.), more than their family has become their real home, a situation in which there is no protection, supervision or direction from responsible adults." (p. 6). Furthermore, UNICEF 1986 (Dabir and Athale, 2011) has also identified three categories of children in difficult situations: children on the street ('home-based' children who return home at night), children of the street ('street-based' children who have less or no family support), and abandoned children (those 'children of the street' who have severed all ties with family and completely survive on their own). However, it has been argued by the authors that these categories do not include children who have been victims of war or disaster, those who are suffering from AIDS or have been orphaned due to AIDS, or for some other complex reason are driven to live on the streets. For this reason, Dabir and Athale (2011) prefer a broader definition of street children that considers only two classifications: home-based and street-based.

The existing statistics on the number of street children both at the national and global level are rather conflicting (Subrahmanyam \& Sondhi, 1990). Estimates provided by different nations are for different times and the methods of estimation have also varied (Dabir \& Athale, 2011). The existing literature on street children is mostly in the form of survey results or evaluation studies carried out by voluntary organizations (e.g., Subrahmanyam \& Sondhi, 1990). Hartjen and Priyadarsini (2012) have provided readers with a clear view of the present situation of street children from various countries and of the legislation that has been enacted, or could be enacted, to secure the welfare and protection of all children. de Moura (2002) has analysed the existing literature on street children, identifying patterns of descriptions and characterizations, and focusing on the factors responsible for the existence of this socially excluded group. Works by Humphries (2003), Schmitz, Traver, and Larson (2004), and Wiener (2009) address the issue of child labour, its origin and economic aspect, its spreading across the world, especially to the developing nations, and the dangers that it poses for children. Several studies on street children have also been conducted in India. Dabir and Athale (2011) compare the living conditions of street children in three different cities of the world, including Mumbai. Bajpai (2006), Phillips (1994), and Chopra (2015) focus mainly on the relevant policies and legal mechanisms. Other case studies on street children in India include those of Chikarmane (1996), and Mathur (2009). 
International Journal of Child, Youth and Family Studies (2018) 9(1): 69-82

\section{The Situation in India}

The situation of street people in India has been well summed up by Phillips (1994, p.11): "The whole family lives on pavement, procreate on pavements." The children belonging to street dwelling families grow up to engage themselves in work from a tender age, so that they may carry some bread back home for the family's sustenance. In Children In India $2012-A$ Statistical Appraisal, the Ministry of Statistics and Program Implementation (2012) stated:

According to the International Labour Organization (ILO), "Born to parents who themselves were uneducated child workers, many child workers are forced to continue a tradition that leaves them chained to a life of poverty" (ILO, United States Policies to Address Child Labour Globally 2010). That is why child labour is a very complicated development issue, affecting human society all over the world. (Ch. 6)

"In India, poverty is high and governmental support is severely limited, so children often serve as a source of family income" (Segal, 1999). Hence, in spite of a standing constitutional fundamental right that prohibits child labour, there has been a disturbing rise in the number of working street children over the years. Humphries (2003) observed that, "Although child labour is hard to document, an alternative way of curbing child labour is by requiring school attendance" (p. 191). UNICEF's State of the World's Children 2012 report states, "The children living in around 49,000 slums in India are invisible." (Save the Children India \& PwC India, 2015 , p. 10). Such dismal statistics reveal that it is indeed difficult to track down the number of working street children especially when the basic count is distorted in the nation.

According to Dabir and Athale (2011), global challenges like poverty, rapid urbanization, overcrowded cities, the uneven distribution of wealth, privatization, and the effects of globalization have resulted in an emerging migration of population, and in turn to growing numbers of people relegated to street life. "Every day millions of children live - and many die - in the streets of the world's cities. Sadly, no nation is spared this shame of shames" (Pemberton, 2007, as cited in Dabir \& Athale, 2011, p. 3).

Researchers have cited various reasons for this rise in the street population, and in the number of working children. While Aptekar (1994) explains the increase with reference to factors like family status and the psychological condition of the child and his or her perceptions about life, others, like Epstein (1996), have highlighted abuses, armed conflicts, natural calamities, and an alteration in family structures as some of the causes. According to the Census of India 2011, the total urban population was 377 million, with a remarkable increase from $17 \%$ in 1950 to $31 \%$ in 2011 (Save the Children India \& PwC India, 2015). Considerably, one of the major reasons for such increase is migration of people that also leads to the growing number of working children in the cities. However, I believe this growing problem could be tackled effectively by a systematic social organization that would not only spread awareness, but would also bring the street children back into mainstream society. 
International Journal of Child, Youth and Family Studies (2018) 9(1): 69-82

\section{Role of Social Intervention}

According to Chikarmane (1996, p. 37), "street identity is created by the media and social work interventionists". Whether the presence of interventionists actually curtails the right of these children to create their own identities is a debatable issue. A contrary theory maintains that these destitute children gain moral support from social work intervention, helping them to feel that they "belong", that they "exist"; and to know that they are no longer alone if they are hurt or unwell (Chikarmane, 1996, p. 37). For children living without families, such social interventions may provide their only support, "their only anchor", as Chikarmane (1996, p. 37) puts it. The type of intervention provided tends to affect the way these children are portrayed - as victims, villains, dependents, or deviants (Panter-Brick, 2002). Thus, it is important for the social interventionists to take utmost care of the type, form, and degree of intervention they render upon the different types of street children. For instance, the kind of intervention required by working street children living with their parents is much different from the degree of intervention lone street children would need or desire. However, in contemporary times, interventionists have changed from a charitable to a rights-based approach, working with children rather than for them, thus giving prime importance to child participation.

\section{The Rights Perspective}

In the twentieth century, with a shift in paradigm from a welfare approach to a rightsbased approach, two primary schools of thought developed regarding child rights: the child liberationist model that uses concepts like individualism, independence, and self-determination to argue that children should be freed from adult control; and the child protectionist model that considers children to be naïve and dependent on adult care. The United Nations Convention on the Rights of the Child was developed from both models (Chopra, 2015). All members of the United Nations have ratified the Convention, except the United States.

Child rights form an integral part of human rights and therefore every child is entitled to civil, economic, social, and cultural rights. What children do not possess are institutionalized political rights. Civil rights of children include the right to a name and nationality, and protection from torture and ill-treatment, along with special rules pertaining to their right to not be deprived of liberty or separated from a parent. Economic rights include the right to benefit from social security, the right to an adequate standard of living to ensure proper development, and protection from exploitation at work. Social rights of children include the right to the highest attainable standard of health and access to medical services, the right to education, the right to special care for disabled children, protection from sexual exploitation and abuse, and the right to adoption. Cultural rights include full participation in creative and cultural activities. A final category of child rights includes the concept of the "three Ps" - Provision, Protection, and Participation. In other words, every child has the right to be provided with the necessities of life, along with services needed for healthy development; the right to be shielded from certain acts and practices; and the right to do things, express oneself, and have an active and effective voice in matters affecting one's life. Both methods of classification are useful in analysing and understanding 
International Journal of Child, Youth and Family Studies (2018) 9(1): 69-82

children's rights. Where one classification shows us, for instance, that children have no political rights, the other highlights the fact that they have limited rights with regard to participation. The criticism sometimes made that the concept and content of child rights are essentially patriarchal and overprotective has no real grounds, as protection is only one element among others as a basis for these rights. Indeed, it is a component both of overall human rights, and of particular rights concerning special groups such as ethnic, linguistic, and religious minorities.

\section{Methodology}

This study focused primarily on access to health and education in street children between 6 and 18 years old in two of the most densely populated metropolitan cities of India, Mumbai and Kolkata. The study also aimed to assess the role and the effectiveness of social work interventions (which are among the protective factors) in ensuring the rights of vulnerable children.

Both quantitative and qualitative research methodologies were employed in this exploratory study. As far as I am aware, no previous attempts have been made to study accessibility to both health and education of street children in these two study areas.

Two categories of street children took part in the study: those who lived with or without their parents in either Kolkata or Mumbai (comprising a total of 80 participants), and those who lived in a night shelter in Mumbai (20 girls). During the study, I also interviewed a small number of social workers and made an attempt to understand their perspective on the children, with whom they had been working for a long time. The total sample comprised 100 children. Data were collected through individual semi-structured interview schedules and nonparticipant observation. A convenience sampling technique was used: the selection of participants depended on the availability of children at the nongovernmental organizations (NGOs) at the time when the interviews were being conducted. The quantitative data collected from the field were sorted, coded, and then analysed through the use of the SPSS statistical tool.

Health and education are vital requirements for children to fulfil their potential. Denial of access to either may result in the "presence of street children as helpless victims of social discrimination" (Panter-Brick, 2002, p. 156). Educating these poor and needy children, giving them social standing, and looking after their well-being and good health will assist the children to become the architects of their own lives.

\section{Findings and Discussion}

Most of the 100 children who were interviewed had families to return to at day's end. In general, their homes were rudimentary, affording little protection from sun, wind, and rain; reeking of the nearby open drains and canals. Such a home could also be called a pavement. 
International Journal of Child, Youth and Family Studies (2018) 9(1): 69-82

Their pastimes and games, which included playing alongside the gutters and fishing from them, were not those of most children of their age.

Although the street children were enrolled in formal schooling, which the NGOs supplemented with in-house informal education by helping with home assignments and providing tutoring, once the children were out of school and away from the interventionists, they tended to forget about the training they had been receiving. Often, the children would return to the centres claiming to have lost a book or stationery, or even their whole school bag, merely due to carelessness, and demand new supplies. This kind of behaviour was common since the children were well aware of the fact that they would receive new supplies even if they had lost their belongings, and therefore, some of them did not bother to take care of their items. Easy availability of amenities projected that the children took this facility for granted. However, the children are not to be blamed for such behaviour, which arose because the streets did not support their education or their well-being. "Parents are often unavailable to assist their children with schoolwork and the chore of completing homework is often unrealistic" for the child (Epstein, 1996, p. 291). The streets did not provide the ambience that might enable these children to make a better choice for themselves. In an interview, one of the toiling interventionists exclaimed, "It seems easy to handle these children, but in actuality, it is very difficult."

Part of the reason interventionists found these children "difficult" was that the children tended to develop their own ideas, which they expected at least the interventionists to acknowledge and respect. Such behavioural patterns are common among children who have been orphaned at a young age and have been struggling to survive on their own, taking their own responsibility and growing up without any adult supervision. They seem markedly more mature and self-sufficient than their peers. Also, children who are on the street may be there due to some specific reason, such as difficulty accepting a new parent following a remarriage, or even sexual abuse by family members. Such events may compel the children to spend more time with the interventionists than within their families.

The centre in Mumbai had a night shelter facility, accommodating destitute, homeless girls up to the age of 18 years. At the time of my visit to the centre, about 50 girls were residing there. For these participants — some of whom had been deserted, were runaways, or were victims of sexual abuse - the centre was their only support system, and they developed an affinity and affection for both the place and the interventionists. One of the responses received from among the 20 participants interviewed seemed to be a reflection of the entire group:

"There is no home to return to. I enjoy staying here, with all my friends. This place provides an ambience that encourages me to study. I get proper meals here, and also enough freedom to enjoy my rights. This is my home now." 
International Journal of Child, Youth and Family Studies (2018) 9(1): 69-82

\section{Findings}

The study revealed a number of causes for the children adopting a street-based lifestyle.

Abject poverty: Figure 1 shows that, for most of the children (83) and their parents, poverty was the major reason they were living on the streets. This was true for the majority of the children in both domains of the study, with the children having been born on the streets. In developing nations, it is observed that with increasing economic marginalization of the poor, the number of street children also increases, leading more people to "procreate on pavements" (Phillips, 1994, p. 11). A survey called "Surviving the Streets", which was conducted on street children in Delhi in 2010 as initiative by Save the Children (2011), mentioned that the cities of Delhi, Mumbai, and Kolkata caters to the largest number of street children. While street-dwellers would be adding more breadwinners to their families, the nation would acquire more street children in need of help.

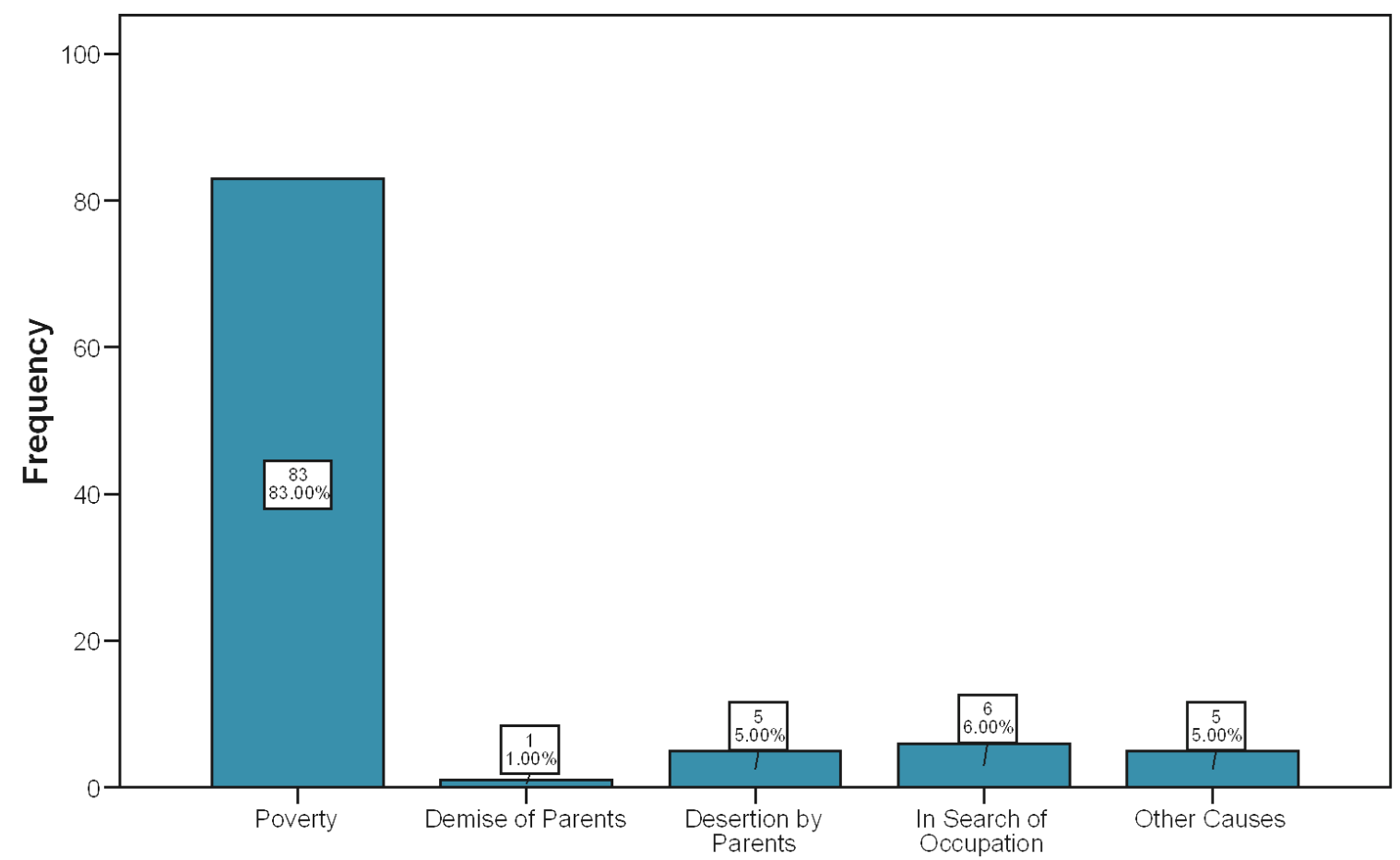

Figure 1. The distribution of circumstances that led the children to streets.

In six cases, street-living began when the parents migrated with their children into the city in search of a better occupation. For another five, desertion by parents led them to become street children, with some fending for themselves under the guidance of the local people in their place of stay; and others, as in some cases found in Kolkata, staying with their grandparents in the city under similar conditions. Five children reported other causes for turning to the streets, such as running away in response to some form of exploitation or separation of parents. Only one participant reported having become a street child following the demise of both parents. 
International Journal of Child, Youth and Family Studies (2018) 9(1): 69-82

Lack of awareness of educational opportunities: The study revealed that a majority of children, especially females, had no access to educational facilities in the pre-intervention period, and that several children who did have access to educational facilities had been studying below the required standard. Thus, the hypothesis may be drawn that female education was not encouraged until intervention was provided to the children in the area, which resulted in a new awareness of educational opportunities among parents and guardians. The fact that the children had been benefiting from their exposure to the social intervention that was being provided was evident from the observation that majority of them showed interest in educating themselves, had set vivid ambitions, and were "dreaming big" for themselves. This trend was more visible among the grown up girls especially the ones residing in the night shelter, who constantly received intervention within the centre premises.

Helping illiterates become aware of educational opportunities seems to be one of the issues most in need of social intervention, even today. However, with the rapid advent of NGOs and other civil society organizations that work extensively for and with the vulnerable, the issue of lack of public awareness is quickly being addressed, especially through the mass media. For instance, advertisements, announcements over the internet, radio, and/or television, awareness camps conducted by various governmental and nongovernmental bodies that address the issues of gender equality, importance of girl child education is being addressed at regular intervals.

Livelihood patterns: Figure 2 depicts the livelihood of the children in the study. The majority of the children (91) were found to belong to a street family, to be staying under parental guidance, and to be dependent on their illiterate parents, who were mainly daily wage earners in the case of fathers and domestic workers in the case of mothers. That these parents were generally unaware of the importance of seeking education or striving for self-development had a strong influence over their children's conceptions about life.

Three of the children were rag-pickers, earning a minimal amount of money for themselves. One was earning a livelihood as a domestic help. Four of the children had other means of livelihood, such as helping their parents at the workplace and selling items; for instance, one of them helped his father in a commercial automotive garage, while the other three children worked to earn their own living (abandoned children). Among the ones residing with their parents (91), many of them just worked to earn pocket money for a new dress or an ice cream, trying to cater to their own petty requirements.

Children learn quickly from their environment, and they tend to copy and abide by the norms and traditions that they have grown up with. Their identities are shaped by these socializations and conventions. Although the children received proper formal as well as informal education after the interventions, a strong sense of gender socialization remained evident, with the girls returning home to help their mothers in household work, and the boys returning home to play with their peers and then waiting for dinner to be served to them. The hope is that the 
children will eventually be able to educate their parents and society, and create identities of their own.

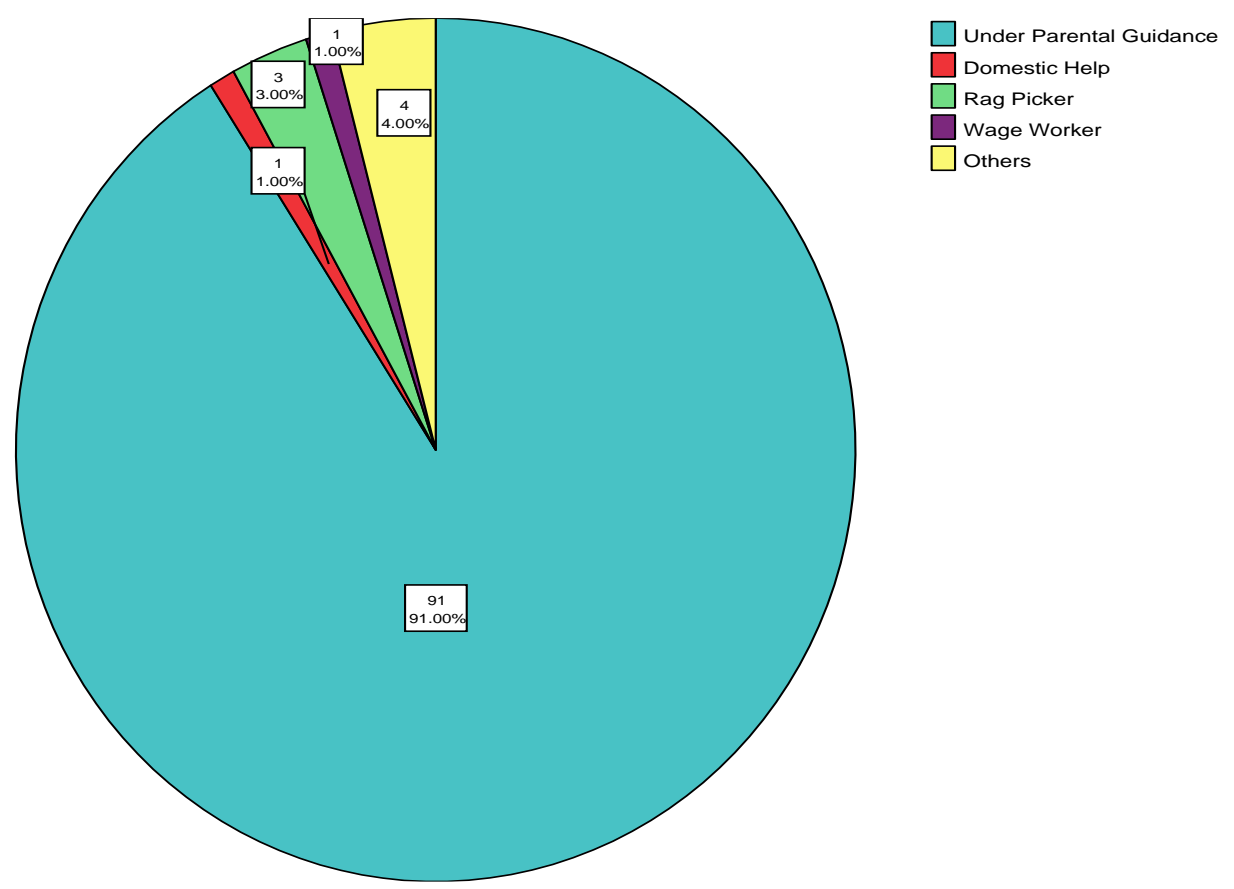

Figure 2. The livelihood of the children.

Dreams and aspirations: It is often said that one cannot sustain life without having aims and aspirations. The same was true in the case of these children. They had set their goals, and the road to achieving them was being smoothed by the meticulous support of the interventionists. Almost a quarter of the children (21) aspired to become doctors, and nearly as many (18, mostly girls) hoped to be teachers. Sixteen children had not decided on a career path, while 12 hoped to join the police force, and 5 hoped to become pilots. The remainder (28) had an assortment of ambitions, with the boys aspiring to be army officials, engineers, or sportsmen such as football players and cricketers, while the girls aspired to become fashion designers, artists, and actors.

An exposure to education through proper channels, and active participation in the vocational courses offered by the centres, helped these children nurture their self-development skills, tap their inner potentials, polish their identities, and strive to achieve their goals in life. Education also provided tools to help the children cope with the societal obstacles and environmental hardships they will inevitably encounter.

Hygiene versus health: The study showed that most children suffered from ailments like malaria, tuberculosis, cold and cough, water-borne diseases, and skin diseases, a result of their unhygienic living conditions. Although most had access to proper toilets, there were still a few unfortunate ones without. The inadequate sanitation facilities in areas of Mumbai and Kolkata 
International Journal of Child, Youth and Family Studies (2018) 9(1): 69-82

not only lead to illness, but pose an especial danger for young girls, who may be sexually harassed due to the lack of privacy. In their article "Acting without sanitation: Open defecation", McFarlane, Desai, \& Graham (2011) reported that, although the Cleanliness and Sanitation Byelaws were established in Mumbai in 2006, women still felt unprotected and insecure due to the lack of proper sanitation facilities in many of Mumbai's urban slums.

However, most children in the current study received proper medical attention when required, since a majority of them lived under parental guidance. All the children also received regular medical examinations from the social interventionists.

Vulnerability to exploitation: The majority of children in this study faced physical abuse, mostly from parental beatings. Almost all of the children, irrespective of gender, said that they were afraid of their parents, because their parents beat them when they were being naughty. The incidence of physical abuse was higher for boys. Sexual exploitation was however predominant only among the girls in the study. Other abuses reported by the participants included calling names, exchanging abusive words, passing inappropriate comments, ragging and bullying younger siblings, and discouraging children who wished to study or expressed ambition. A UNICEF (2006) report, "Behind closed doors: Impact of domestic violence on children", estimated that 27.1 million to 69 million children were exposed to domestic violence in India, while a study conducted by the Ministry of Women and Child Development in 2007 found that a total of $54.5 \%$ of street children reported incidences of sexual abuse (Save the Children India \& PwC, 2015).

The children learned to survive with their daily fears, and to remain alert about their surroundings, not sure when they might be victimized. A ten-year-old girl spoke about such fears when she said,

"My sister goes very far every day to fetch water for our daily needs, and I stay alone at home. I am not scared of ghosts, but of people."

Maturity beyond age: Another observation that was subtly evident from the study was the fact that the hardships of life as a street child could take away the innocence of childhood and lead one to become mature beyond one's years. The participants in this study survived street life on their own terms. When a 13-year-old who was being reared by a single parent spoke, his words brought out the level of maturity and responsibility he had attained at such a tender age:

I don't know why we don't stay with our father, but I respect my mother's decisions and have learnt to live without him now. I don't wish to know the reasons for their separation, hence I don't bother my mother with such questions.

Another child who lived with her grandparents after being abandoned by her family stated that she felt bad but had somehow accepted the fact that her parents were willing to look after her 
International Journal of Child, Youth and Family Studies (2018) 9(1): 69-82

siblings, but for reasons unknown would not take her back. She said, "I am the most deprived and unlucky one of my parents' [children] to have been disowned this way."

\section{Discussion}

Through this study, I have tried to identify the role of social intervention in ensuring some of the basic rights of street children. Drawing from existing literature, Dybicz (2005) presented an overview of the kinds of intervention needed by the various categories of children: those who have not yet taken to the streets, those who have chosen street life but have family contact, and those who are entirely on their own. However, in a developing nation like India that struggles to sustain a huge population, it is a difficult task to provide educational intervention to all children in need of it. Establishing different kinds of NGOs to support all the categories of street children is indeed a challenging effort for India. Some articles on street children, like those by Chikarmane (1996), Dabir and Athale (2011), and Hartjen and Priyadarsini (2012), reevaluate the size of the ever-growing problem of street children, highlighting the menaces of urbanization, poverty, abuse, culture differences, and other modernizing factors that lead to such phenomena. This paper also addresses similar issues, like poverty, lack of parental awareness, and globalization, that have led the children to be on the streets. However, the findings have been mostly based on empirical data, and as suggested by Martins and Ebrahim (1993), there is a need for qualitative research on street children in order to gain a better understanding of their emotions, the hardships of life on the streets, and their coping strategies. In a study conducted by Aptekar in 1993 (as cited in Aptekar, 1994), it was pointed out that, in developing nations, more street boys than girls are born. In a nation where even today, a boy child is often preferred over a girl child, it is perhaps not unexpected that more boys would be trying to earn a living for their families on the streets, and that the girls would be kept back in the household to run the daily errands. Amidst such gender socializations, the role of the NGOs, which strive to educate and empower the street children and to create awareness on gender equality, has been well defined. Likewise, my study has revealed that most of the girls had no access to education in the preintervention period, and that very few boys helped their mothers in daily household work. Very few have been able to break free of stereotypical gender roles.

Chikarmane (1996) highlighted the fact that intervention is a way of restoring street children to mainstream society, but also explained how essential it is for interventionists to respect the "street identity" of these children, and simultaneously to take care of their needs. While it is not easy for the children to accept the changes needed to bring them into mainstream society, it is a bigger challenge for the interventionists to encourage those changes without harming or alienating the children. This paper has also emphasized some of the challenges that the interventionists face when dealing with street children. 
International Journal of Child, Youth and Family Studies (2018) 9(1): 69-82

\section{Conclusion}

This study shows that street children, whether with their families or on their own, are especially vulnerable to the dangers of society. Poverty is seen to be the leading cause for their being on the streets. While most of the children lived under parental guidance, receiving some care and security, all nevertheless faced hardships and challenges every day.

The challenge of mainstreaming this section of society has indeed been difficult for social interventionists over the years; however, many studies are now providing promising indications that, given the present success rate of the interventionists, the task is not impossible. The outlook of parents and society is changing, with an increase in girl-child education and a reduction in gender disparities. Initiatives by the United Nations, NGOs like Save the Children India, and government initiatives like the Integrated Child Protection Scheme are not only helping in creating awareness but are also attempting to reverse the continuing increase in the number of vulnerable children in the nation. A "holistic service structure" for the protection of all children has been the new approach of all stakeholders (Save the Children India \& PwC India, 2015, p. 141).

The multiple issues explored and studied while conducting this research include the reasons for living on the streets, whether the children had family support or the company of friends while on the streets, the number of years the children had been receiving social work intervention, access of the children to educational facilities in the pre- and post-intervention

periods, and access of the children to health facilities in those periods. Findings in the two study areas have highlighted the positive role of social work interventionists, and other circumstances responsible for impacting and altering the lives of the children. This study has led to a holistic understanding of the socioeconomic profile of street children, underlining the areas of deprivation and the necessity to overcome them in order to promote a better future for these children. 
International Journal of Child, Youth and Family Studies (2018) 9(1): 69-82

\section{References}

McFarlane, C., Desai, R. \& Graham, S. (2011). Acting without sanitation: Open defecation. Durham, UK: Department of Geography, Durham University. Retrieved from https://www.dur.ac.uk/geography/everyday_sanitation/acting_without_sanitation/

Aptekar, L. (1994). Street children in the developing world: A review of their condition. CrossCultural Research, 28(3), 195-224. doi:10.1177/106939719402800301

Bajpai, A. (2006). Child rights in India: Law, policy and practice (2nd ed.). New Delhi, India: Oxford University Press.

Chikarmane, P. (1996). Street identity. Indian Journal of Social Work, 57(1), 33-38.

Ministry of Statistics and Programme Implementation.(2012). Children in India $2012-A$ statistical appraisal. New Delhi, India: Government of India. Retrieved from http://mospi.nic.in/sites/default/files/publication_reports/Children_in_India_2012-rev.pdf

Chopra, G. (2015). Child rights in India: Challenges and social action. New Delhi, India: Springer.

Dabir, N., \& Athale, N. (2011). From street to hope: Faith based and secular programs in Los Angeles, Mumbai and Nairobi for street living children. New Delhi, India: Sage Publications.

de Moura, S. L. (2002). The social construction of street children: Configuration and implications. British Journal of Social Work, 32(3), 353-367. doi:10.1093/bjsw/32.3.353

Dybicz, P. (2005). Interventions for street children: An analysis of current best practices. International Social Work, 48(6), 763-771. doi:10.1177/0020872805057083

Epstein, I. (1996). Educating street children: Some cross-cultural perspectives. Comparative Education, 32(3), 289-302. doi:10.1080/03050069628722

Hartjen, C. A., \& Priyadarsini, S. (2012). The global victimization of children: Problems and solutions. Berlin, Germany: Springer.

Humphries, J. (2003). Child labor: Lessons from the historical experience of today's industrial economies. The World Bank Economic Review, 17(2), 175-196. doi:10.1093/wber/lhg016

Martins, S. B., \& Ebrahim, G. J. (1993). Street children. Journal of Tropical Pediatrics, 39(5), 264-268.

Mathur, M. (2009). Socialisation of street children in India: A socio-economic profile. Psychology Developing Societies, 21(2), 299-325. doi:10.1177/097133360902100207 
International Journal of Child, Youth and Family Studies (2018) 9(1): 69-82

Panter-Brick, C. (2002). Street children, human rights, and public health: A critique and future directions. Annual Review of Anthropology, 31, 147-171. doi:10.1146/annurev.anthro.31.040402.085359

Phillips, W. S. K. (1994). Street children in India. Jaipur \& New Delhi, India: Rawat Publications.

Save the Children. (2011). Surviving the streets: A study on street children in Delhi [News release]. Retrieved from https://www.savethechildren.in/news/surviving-the-streets-acensus-of-street-children-in-delhi

Save the Children India, \& PwC India. (2015). Forgotten Voices: The world of urban children in India. New Delhi, India: Author. Retrieved from https://www.pwc.in/assets/pdfs/publications/urban-child/urban-child-india-report.pdf

Schmitz, C. L., Traver, E. K. \& Larson, D. (Eds.). (2004). Child labor: A global view. Westport, Connecticut: Greenwood Press.

Segal, U. A. (1999). Children are abused in eastern countries: A look at India. International Social Work, 42(1), 39-52. doi:10.1177/002087289904200105

Subrahmanyam, Y. S., \& Sondhi, P. (1990). Child porters: Psychosocial profile of street children. Indianl Journal of Social Work, 51, 577-582. Retrieved from https://journals.tiss.edu/archive/index.php/ijswarchive/article/view/2227

UNICEF. (2006). Behind Closed Doors: The Impact of Domestic Violence on Children. Littlehampton, UK: The Body Shop International. Retrieved from https://www.unicef.org/media/files/BehindClosedDoors.pdf

Wiener, G. (Ed.). (2009). Child labor (Global viewpoints). Farmington Hills, MI: Greenhaven Press. 